\title{
Psychometric Assessment Using Classic Neuropsychological and Virtual Reality Based Test: A Study in Obsessive-Compulsive Disorder (OCD) and Schizophrenic Patients
}

\author{
Filippo La Paglia ${ }^{1(\bowtie)}$, Caterina La Cascia ${ }^{1}$, Pietro Cipresso ${ }^{2}$, \\ Rosalinda Rizzo ${ }^{1}$, Antonio Francomano ${ }^{1}$, Giuseppe Riva ${ }^{2,3}$, \\ and Daniele La Barbera ${ }^{1}$ \\ ${ }^{1}$ Department of Experimental Biomedicine and Clinical Neurosciences, \\ University of Palermo, G. La Loggia $n^{\circ}$ 1, 90129 Palermo, Italy \\ filippo.lapaglia@unipa.it \\ 2 Applied Technology for Neuro-Psychology Lab, \\ IRCCS Istituto Auxologico Italiano, Via L. Ariosto, 13, 20145 Milan, Italy \\ 3 Department of Psychology, Catholic University of Milan, \\ Largo Gemelli, 1, Milan, Italy
}

\begin{abstract}
Assessment of neurocognitive functioning is a critical task in clinical settings. In many disorders, cognitive impairment precedes the onset of behavioral symptoms, and cognitive decline is a major factor contributing to functional disability. The purpose of the current study was to evaluate the executive functions by comparing the evaluations obtained using a neuropsychological battery with the one obtained using the virtual reality version of the Multiple Errands Test (V-MET). The study population included three groups: 10 patients affected by Obsessive Compulsive Disorder (OCD); 10 Schizophrenic patients; 10 healthy Controls. The results identified executive problems in clinical samples. By contrast, controls have higher level of efficiency and better performance. The correlation across the two assessment support the validity of V-Met, as a neurocognitive assessment.
\end{abstract}

Keywords: Obsessive-compulsive disorder - Schizophrenia - Virtual reality • Neuropsychological assessment

\section{Introduction}

Cognitive and executive functions are often impaired in different clinical disorders, such as dementia, attention deficit hyperactivity disorder, schizophrenia [1] and obsessive compulsive disorder. In schizophrenia, cognitive impairments are often found in multiple areas, including visual information processing [2, 3]; attention [4]; working memory [5]; short-term memory and learning [6]; executive functioning [7]; speed of processing [8]; reasoning and problem solving [9]; context processing [10] and social perception and cognition [11].

The impairment of executive functions called "dysexecutive syndrome", are common in neurological patients and are related to brain dysfunction specifically in the 
prefrontal cortex [12]. Individuals who have an impairment of executive functions show problems of starting and stopping activities, a difficulty in mental and behavioral shifts, an increased distractibility and difficulties in learning new tasks [13]. The executive functions, defined as higher order cognitive functions needed for performing complex tasks [14], are often impaired also in patients with Obsessive Compulsive Disorder (OCD) which are characterized by the impairment of several skills such as attention, planning, problem-solving and behavioral control [15]. Further, OCD is often associated with impairments of visuospatial skills [16], and of memory functioning, including visual, verbal, and numerical [17].

Therefore, no single profile of cognitive deficits has been found to characterize all patients; the majority have impaired ability in at least one area of functioning and a standardized platform for assessing neurocognitive functioning is an important aspect of comprehensive treatment and research for this and other conditions.

Traditionally, cognitive assessment has made use of standardized paper-and-pencil batteries such as Tower London to assess the capacity of planning, Frontal Assessment Battery-FAB to assess the presence and the severity of a dysexecutive syndrome affecting both cognition and motor behavior, Trail Making Test to investigate the visual attention and task switching. However, the neurocognitive assessment under typical clinical laboratory condition are unsatisfactory because it present trials independent from any activities of daily living, and for this reason lacking in ecological validity [18]. Increasing the ecological validity of neuropsychological assessment is important since this will increase the likelihood that patient's cognitive and behavioural responses will replicate the response that would occur in real-life situation [19]. There are also tools developed to measure executive deficits in situations similar to daily ones, such as the Behavioral Assessment of Dysexecutive Syndrome, the Dysexecutive Questionnaire (BADS \& DEX) [20] and the Multiple Errands Test (MET) [13]. The MET is an assessment of executive functions in daily life originally developed by Shallice and Burgess specifically for high functioning patients It consists of three tasks that abide by certain rules and is performed in a mall-like setting or shopping center. Being a "reallife" multitasking test requiring the performance of very common daily actions, the MET has good ecological validity [19]. It also has good psychometric properties [21]. The assessment of executive functions in real-life settings has the advantage of giving a more accurate estimate of the patient's deficits than within laboratory conditions [22], but it required that users to go with the therapist to a real mall, with walking and mobility abilities required for both reaching the target place and moving into and around the mall. This could present a problem if the patient has motor difficulties. In addition, this procedure could take a long time, for both patient and therapist, which could instead be used for more training in the rehabilitative setting. Finally, real shop features and structure are totally uncontrolled by the therapist, so that unpredictable and potentially disturbing changes may occur when the test takes place.

For this reason, the use of simulated environments, perceived by the user as comparable to real world objects and situations, can overcome the limits of the traditional MET, by maintaining its several advantages [23].

Virtual reality is one of the emerging tools with great potential for use in rehabilitation [23]. It involves the use of advanced technologies to produce a simulated environment that users perceive as comparable to real world objects and events [23]; 
moreover it ensure the chance to objectively measure behavior in challenging but safe and ecologically valid environments, while maintaining strict experimental control over stimuli delivery and measurement.

To increase ecological validity of a neuropsychological battery we used advanced technologies capable of providing an ecologically valid context for the patient while he or she is involved in a complex planning task. The specific goal of this study is aimed at developing a tool for the assessment of cognitive and executive functions in patients with different disorders, in particular in patients affected by Obsessive Compulsive Disorder (OCD) and patients suffering from schizophrenia, by the use of virtual reality version of the Multiple Errands Test [13, 24-27].

\subsection{The Virtual Multiple Errands Test}

The virtual environment is a supermarket (Fig. 1), performed in a shopping setting where there are items to be bought and information to be obtained [13, 25]. In particular, subjects were invited to buy some items following a defined shopping list (e.g., a chocolate bar or two products from the refrigerated products aisle) and to obtain some information (e.g., the closing time of the supermarket or the number of shelves which sell fruit) following specific rules:

- you must complete all tasks but you can choose any order;

- you are not allowed to enter any aisle unless you need items to complete part of your task;

- you are not allowed to go into the same aisle more than once;

- you are not allowed to buy more than two items for item category;

- take as little time as possible to complete this exercise without rushing excessively;

- do not speak to the person observing you unless this is part of the exercise.

After explanations of tasks and rules, patients can plan and choose the sequence of actions to complete the tasks. In this way, many different executive functions are stimulated, from the ability to plan a sequence of actions, to problem solving and to cognitive and behavioral flexibility. The tester follow the participant, recording every kind of mistake. While completing the procedure, the time of execution, total errors, inefficiencies, rules breaks, strategies, interpretation failures and partial tasks failures were measured. Specific items of partial task failures are:

- "searched item in the correct area";

- "maintained task objective to completion";

- "maintained sequence of the task";

- "divided attention between components of task and components of other VMET tasks";

- "organized materials appropriately throughout task";

- "self corrected upon errors made during the task";

- "no evidence of perseveration";

- "sustained attention throughout the sequence of the task, not distracted by other stimuli. 


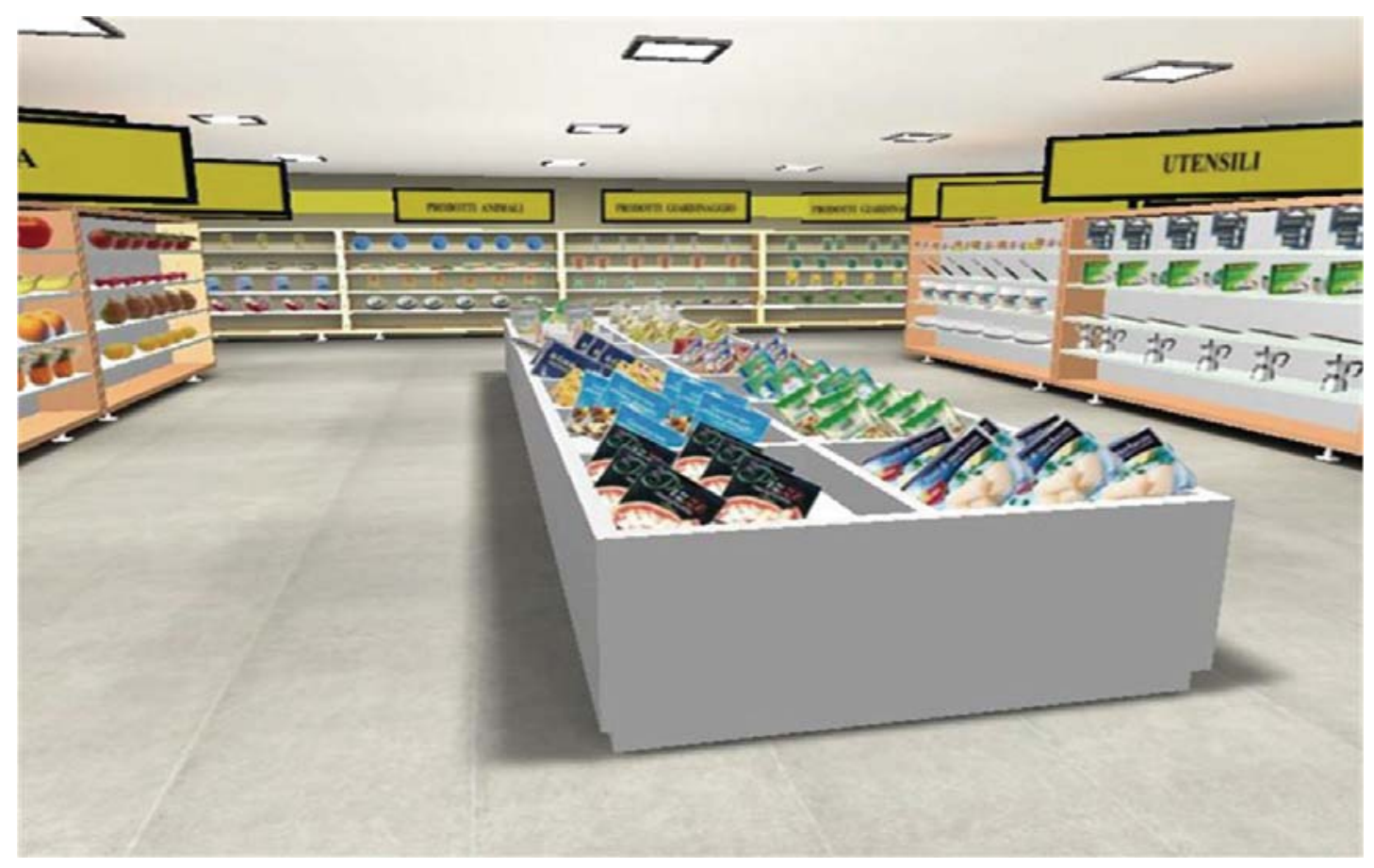

Fig. 1. Virtual Version of the Multiple Errand Test (V-MET).

\section{Methods}

\subsection{Participants}

The study included 10 healthy participants (controls) with no history of psychiatric disorder and two different clinical samples, consisting of 10 patients affected by Obsessive Compulsive Disorder (OCD) and 10 patients suffering from Schizophrenia, recruited from the Outpatient Unit of Psychiatry of Palermo University Hospital.

Patients were excluded from the study based on severe cognitive impairment (MMSE < 19), a severe motor impairment which did not allow subjects to perform the procedure, auditory language comprehension difficulties (score at the Token Test $<26,5$ ), object recognition impairments (score at the Street Completion Test $<2,25$ ), excessive state and trait anxiety (score at the State and Trait Anxiety Index $>40$ ) and excessive depression state (score at the Beck Depression Inventory $>16$ ).

\subsection{The Neuropsychological Evaluation}

Besides the V-MET, participants were tested with exhaustive neuropsychological assessment, to obtain an accurate overview of their cognitive functioning in order to be compared with the performance on the experimental test. In particular, the following neuropsychological tests were employed: Trail Making Test (TMT, Forms A, B and BA) to assess selective attention and Tower of London test (ToL) to assess executive functions. Scores of the tests were corrected for age, education level and gender where appropriate. 


\subsection{Procedure}

After the neuropsychological evaluation, we used the Virtual Multiple Errands Test (VMET), developed by using NeuroVR 2.0 software [26]. V-MET has been already used in many clinical studies involving patients [25, 28-30]. Virtual environments employed in the study present two different scenarios: a food market for the training in navigation and objects selection, and a supermarket (which is larger and more complex environment), for the experimental phase. In this version, after a training session, the subjects were requested to select and to buy various products presented on shelves with the aid of a joy-pad. The products were presented in categories including beverages, fruits and vegetables, breakfast foods, hygiene products, frozen foods, garden products and animal products.

\section{Results}

The three groups were similar in terms of gender, age, education level.

Descriptive statistics for neuropsychological test and VMET tests are reported in Table 1. One-way analyses of variance (ANOVAs) were used to compare patients and controls performance. A Linear Discriminant Analysis (LDA) classification has been used to test the strength of an automatic classification in comparing the three groups (Fig. 2). Main effect showed statistical significant effects for all measures. To compare

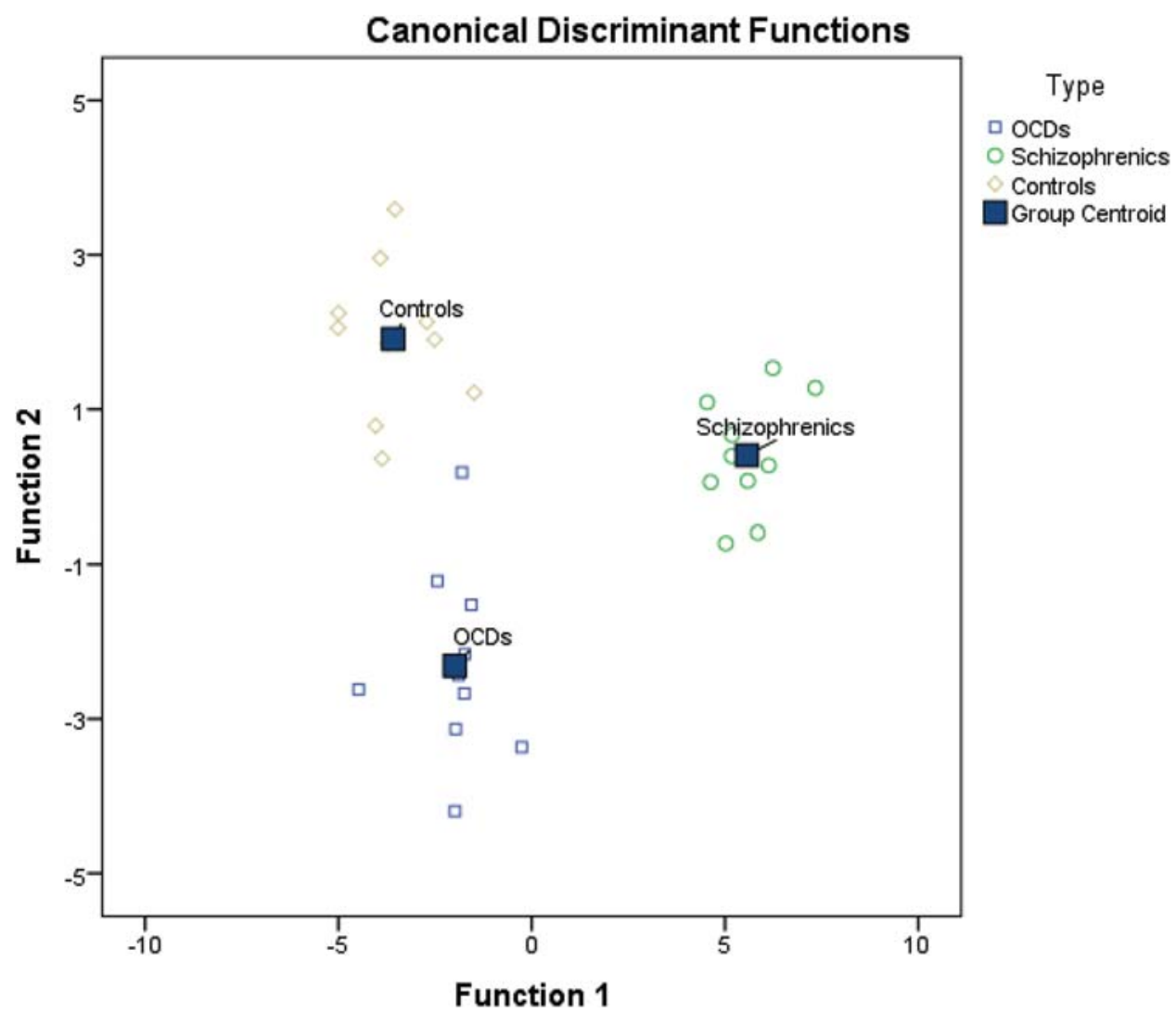

Fig. 2. Classification based on classic LDA gives clear different groups also. 
Table 1. Descriptives for neuropsychological test and VMET tests.

\begin{tabular}{|c|c|c|c|c|c|c|}
\hline & \multicolumn{6}{|l|}{ Type } \\
\hline & \multicolumn{2}{|l|}{ OCDs } & \multicolumn{2}{|c|}{ Schizophrenics } & \multicolumn{2}{|l|}{ Controls } \\
\hline & Statistic & Std. error & Statistic & Std. error & Statistic & Std. error \\
\hline MMSE & 26.0140 & 1.04407 & 23.8370 & 1.41101 & 28.1790 & .13125 \\
\hline FAB & 15.0290 & .41896 & 11.3700 & 1.17882 & 16.4190 & .22999 \\
\hline TMT B-A & 159.60 & 43.231 & 176.70 & 28.826 & 63.49 & 19.089 \\
\hline Tol & 18.8000 & 1.79382 & 20.2000 & 2.67416 & 29.5000 & .73409 \\
\hline Errors & 17.10 & .737 & 19.40 & .921 & 13.50 & .428 \\
\hline Inefficiencies & 22.30 & 1.660 & 19.40 & 1.108 & 28.50 & .872 \\
\hline Strategies & 35.50 & 2.758 & 42.20 & .892 & 29.50 & 1.628 \\
\hline $\begin{array}{l}\text { Sustained } \\
\text { attention }\end{array}$ & 7.8000 & .24944 & 9.6000 & .76303 & 7.6000 & .16330 \\
\hline $\begin{array}{l}\text { Divided } \\
\text { attention }\end{array}$ & 12.0000 & .95452 & 10.2000 & 67987 & 7.8000 & .29059 \\
\hline No perseveration & 7.9000 & .27689 & 9.6000 & .70238 & 7.6000 & .26667 \\
\hline
\end{tabular}

the three groups a post hoc analysis with opportune correction of p-values has been performed and is showed in Table 2.

Table 2. Multiple comparisons between controls and patients for neuropsychological test and V-MET tests.

\begin{tabular}{|c|c|c|c|c|}
\hline Dependent variable & Controls Vs. & Mean difference (I-J) & Std. error & Sig. \\
\hline \multirow[t]{2}{*}{ MMSE } & $O C D s$ & 2.16500 & 1.43718 & .372 \\
\hline & Schizophrenics & $4.34200^{*}$ & 1.43718 & .016 \\
\hline \multirow[t]{2}{*}{$\mathrm{Fab}$} & $O C D s$ & 1.39000 & 1.03861 & .472 \\
\hline & Schizophrenics & $5.04900^{*}$ & 1.03861 & .000 \\
\hline \multirow[t]{2}{*}{ TMT B-A } & $O C D s$ & -96.114 & 45.198 & .123 \\
\hline & Schizophrenics & -113.214 & 45.198 & .055 \\
\hline \multirow[t]{2}{*}{ ToL } & OCDs & $10.700^{*}$ & 2.697 & .001 \\
\hline & Schizophrenics & $9.300^{*}$ & 2.697 & .006 \\
\hline \multirow[t]{2}{*}{ Errors } & OCDs & $-3.600^{*}$ & 1.025 & .005 \\
\hline & Schizophrenics & $-5.900^{*}$ & 1.025 & .000 \\
\hline \multirow[t]{2}{*}{ Inefficiences } & OCDs & $6.200^{*}$ & 1.778 & .005 \\
\hline & Schizophrenics & $9.100^{*}$ & 1.778 & .000 \\
\hline \multirow[t]{2}{*}{ Strategies } & $O C D s$ & -6.000 & 2.714 & .103 \\
\hline & Schizophrenics & $-12.700^{*}$ & 2.714 & .000 \\
\hline \multirow[t]{2}{*}{ Sustained attention } & OCDs & -.20000 & .66889 & .987 \\
\hline & Schizophrenics & $-2.00000^{*}$ & .66889 & .018 \\
\hline \multirow[t]{2}{*}{ Divided attention } & OCDs & $-4.20000^{*}$ & .98583 & .001 \\
\hline & Schizophrenics & -2.40000 & .98583 & .064 \\
\hline \multirow[t]{2}{*}{ No perseveration } & $O C D s$ & -.30000 & .65376 & .957 \\
\hline & Schizophrenics & $-2.00000^{*}$ & .65376 & .015 \\
\hline
\end{tabular}

*The mean difference is significant at the 0.05 level. 


\section{Discussion}

Results showed a statistical significant difference between the three groups. An analysis of Post hoc tests showed also deeper interrelationship and differences among the three groups, comparing pairs (Table 2).

In the recent decades, neuropsychology, cognitive psychology and cognitive neuroscience have been worked together to understand the complexity of cognitive processes, the functional neuroanatomy underpinning those cognitive domains, and the implications of cognitive impairments in neurological patients for models of normal cognitive functioning. Classical Neuropsychological tests have been extensively used for the assessment of executive functions in OCD and Schizophrenics patients. Nonetheless under the umbrella of these cognitive functions more specific needs need to be considered and V-MET seems to be an instrument that fit well this purpose.

Our results showed that neuropsychological test of executive functions, and in particular FAB, TMT B-A and ToL, are not always able to be so precise to have a different effect compared with the controls, even because according to mini-mental (MMSE) the cognitive levels of patients and controls may differ (Table 2).

Cognitive assessment of executive functions needs more ecological validation to be included in neuropsychological test and, in this sense, V-MET seems to be more sensitive to effects and changes in executive sphere of patients and controls.

In particular, V-MET measures showed to be very sensitive in comparing controls to both OCDs and Schizophrenics. Even if the OCDs appears to be similar to controls according to MMSE e FAB, V-MET measures catch differences in the executive sphere separating also different domain of analyses.

Patients make more errors. More based on mean score of inefficiencies and strategies, patients show a more inefficient behavior, for example don't use the market map, don't check instructions and don't use references for orienting, among the others. More, scores for divided attention and no perseveration (persevering in errors is a clear sign of reduced flexibility) are lower in controls (the lower is the score, the better is the performance). On the basis of these results patients showed difficulties in mental flexibility and in the task for which divided attention is required. Consequently, patients are not able to recognize own errors and autocorrect (reduced cognitive flexibility typical in patients), modifying their behavior and their strategies based on the goal to reach. Results supports validity and flexibility in using V-MET as an assessment tool for executive functions.

Acknowledgements. Dr. Cipresso reports having received research funds through the research project NeuroVirtual 3D, funded by Regione Piemonte (Grant No. FA211-432C-2012).

The Authors wish to thanks the anonymous Referees for the meaningful suggestions that significantly improved the paper. 


\section{References}

1. Lo Priore, C., Castelnuovo, G., Liccione, D.: Experience with V-STORE: considerations on presence in virtual environments for effective neuropsychological rehabilitation of executive functions. Cyberpsychol. Behav. 6(3), 281-287 (2003)

2. Green, M.F.: Schizophrenia from a neurocognitive perspective. Allyn \& Bacon, Boston (1998)

3. Knight, R.A., Silverstein, S.M.: The role of cognitive psychology in guiding research on cognitive deficits in schizophrenia. In: Lenzenweger, M.F., Dworkin, R.H. (eds.) Origins and Development of Schizophrenia: Advances in Experimental Psychopathology, pp. 247-295. American Psychological Association, Washington, DC (1998)

4. Silverstein, S.M., Light, G.A., Palumbo, D.R.: The sustained attention test: a measure of cognitive dysfunction. Comput. Hum. Behav. 14, 463-475 (1998)

5. Docherty, N.M., Hawkins, K.A., Hoffman, R.E., Quinlan, D., Rakfeldt, J., Sledge, W.H.: Working memory, attention, and communication disturbances in schizophrenia. J. Abnorm. Psychol. 105, 212-219 (1996)

6. Calev, A., Korin, Y., Kugelmass, S., Lerer, B.: Performance of chronic schizophrenics on matched word and design recall tasks. Biol. Psychiatry 22, 699-709 (1987)

7. Brazo, P., Delamillieure, P., Morello, R., Halbecq, L., Marie, R.M., Dolfus, S.: Impairments of executive/attentional functions in schizophrenia with primary and secondary negative symptoms. Psychiatry Res. 133(1), 45-55 (2005)

8. Braff, D.L., Saccuzzo, D.P.: Effect of antipsychotic medication on speed of information processing in schizophrenic patients. Am. J. Psychiatry 139, 1127-1130 (1982)

9. Chan, R.C., Chen, E.Y., Cheung, E.F., Chen, R.Y., Cheung, H.K.: Problem solving ability in chronic schizophrenia: a comparison study of patients with traumatic brain injury. Eur. Arch. Psychiatry Clin. Neurosci. 254, 236-241 (2004)

10. Cohen, J.D., Barch, D.M., Carter, C., Servan-Schreiber, D.: Context-processing deficits in schizophrenia: converging evidence from three theoretically motivated cognitive tasks. J. Abnorm. Psychol. 108, 120-133 (1999)

11. Green, M.F., Olivier, B., Crawley, J., Penn, D., Silverstein, S.: Social cognition in schizophrenia: recommendations from the MATRICS new approaches conference. Schizophr. Bull. 31, 882-887 (2005)

12. Baddeley, A.D., Wilson, B.A.: Frontal amnesia and the dysexecutive syndrome. Brain Cogn. 7, 31-44 (1988)

13. Shallice, T., Burgess, P.W.: Deficits in strategy application following frontal lobe damage in man. Brain 114, 727-741 (1991)

14. Godefroy, O.: Frontal syndrome and disorders of executive functions. J. Neurol. 250(1), 1-6 (2003)

15. Burgess, P.W., Alderman, N.: Executive dysfunction. In: Goldstein, L.H., McNeil, J.E. (eds.) Clinical Neuropsychology: A Practical Guide to Assessment and Management for Clinicians, pp. 185-209. Wiley, Chichester (2004)

16. Hollander, E., Cohen, L., Richards, M., Mullen, L., De Caria, C., Stern, Y.: A pilot study of the neuropsychology of obsessive-compulsive disorder and Parkinson's disease: basal ganglia disorders. J. Neuropsychiatry Clin. Neurosci. 5, 104-106 (1993)

17. Martinot, J.L., Allilaire, J.F., Mazoyer, B.M., Hantouche, E., Huret, J.D., Legaut-Demare, F., Deslauries, A.G., Pappata, S., Baron, J.C., Syrota, A.: Obsessive-compulsive disorder: a clinical, neuropsychological and positron emission tomography study. Acta Psychiatr. Scand. 82, 233-242 (1990) 
18. Goldstein, G.: Functional considerations in neuropsychology. In: Sbordone, R.J., Long, C.J. (eds.) Ecological Validity of Neuropsychological Testing, pp. 75-89. GR Press/St. Lucie Press, Delray Beach (1996)

19. Burgess, P.W., Alderman, N., Forbes, C., Costello, A., Coates, L.M., Dawson, D.R., Anderson, N.D., Gilbert, S.J., Dumontheil, I., Channon, S.: The case for the development and use of "ecologically valid" measures of executive function in experimental and clinical neuropsychology. J. Int. Neuropsychol. Soc. 12(2), 194-209 (2006)

20. Wilson, B.A., Alderman, N., Burgess, P.W., Emslie, H., Evans, J.J.: Behavioural Assessment of the Dysexecutive Syndrome. Harcourt Assessment, London (1996)

21. Knight, C., Alderman, N., Burgess, P.W.: Development of a simplified version of the multiple errands test for use in hospital settings. Neuropsychol. Rehabil. 12, 231-255 (2002)

22. Rand, D., Weiss, P.L., Katz, N.: Training multitasking in a virtual supermarket: a novel intervention after stroke. Am. J. Occup. Ther. 63, 535-542 (2009)

23. Rizzo, A.A., Kim, G.: A SWOT analysis of the field of virtual rehabilitation and therapy. Presence 14, 1-2 (2005)

24. Fortin, S., Godbout, L., Braun, C.M.J.: Cognitive structure of executive deficits in frontal lesioned head trauma patients performing activities of daily living. Cortex 39, 273-291 (2003)

25. Raspelli, S., Carelli, L., Morganti, F., Poletti, B., Corra, B., Silani, V., Riva, G.: Implementation of the Multiple Errands Test in a NeuroVR-supermarket: a Possible Approach. Stud. Health Technol. Inform. 154, 115-119 (2010)

26. Riva, G., Gaggioli, A., Grassi, A., Raspelli, S., Cipresso, P., Pallavicini, F., Vigna, C., Gagliati, A., Gasco, S., Donvito, G.: NeuroVR-2 a free virtual reality platform for the assessment and treatment in behavioral health care. Stud. Health Technol. Inform. 163, 493-495 (2011)

27. Raspelli, S., Pallavicini, F., Carelli, L., Morganti, F., Pedroli, E., Cipresso, P., Poletti, B., Corra, B., Sangalli, D., Silani, V., Riva, G.: Validating the neuro VR-based virtual version of the multiple errands test: preliminary results. Presence: Teleoper. Virtual Environ. 21(1), 31-42 (2013)

28. La Paglia, F., La Cascia, C., Rizzo, R., Sideli, L., Francomano, A., La Barbera, D.: Cognitive rehabilitation of schizophrenia through NeuroVR training. Stud. Health Technol. Inform. 191, 158-162 (2013)

29. La Paglia, F., La Cascia, C., Rizzo, R., Riva, G., La Barbera, D.: Assessment of executive functions in patients with obsessive compulsive disorder by neuro VR. Stud. Health Technol. Inform. 181, 98-102 (2012)

30. Carelli, L., Morganti, F., Poletti, B., Corra, B., Weiss, P.L., Kizony, R., Silani, V., Riva, G.: A neuroVR based tool for cognitive assessment and rehabilitation of post-stroke patients: two case studies. Stud. Health Technol. 144, 243-247 (2009)

31. Cipresso, P., La Paglia, F., La Cascia, C., Riva, G., Albani, G., La Barbera, D.: Break in volition: a virtual reality study in patients with obsessive-compulsive disorder. Exp. Brain Res. 229, 443-449 (2013). doi:10.1007/s00221-013-3471-y

32. Pedroli, E., Cipresso, P., Serino, S., Pallavicini, F., Albani, G., Riva, G.: Virtual multiple errands test: reliability, usability and possible applications. Stud. Health Technol. Inform. 191, 38-42 (2013). doi:10.3233/978-1-61499-282-0-38

33. Pedroli, E., Cipresso, P., Serino, S., Albani, G., Riva, G.: A virtual reality test for the assessment of cognitive deficits: usability and perspectives. In: Proceedings of the 2013 7th International Conference on Pervasive Computing Technologies for Healthcare and Workshops, pervasive health 2013, 5-8 Maggio 2013, pp. 453-458 (2013). ISBN: 978193696880-0, doi:10.4108/icst.pervasivehealth.2013.252359 
34. Cipresso, P., Serino, S., Pedroli, E., Albani, G., Riva, G.: Psychometric reliability of the neuroVR-based virtual version of the Multiple Errands Test. In: Proceedings of the 2013 7th International Conference on Pervasive Computing Technologies for Healthcare and Workshops, pervasive health 2013, 5-8 Maggio 2013, pp. 446-449 (2013). ISBN: 978193696880-0, doi:10.4108/icst.pervasivehealth.2013.252361 